\title{
Association between transcription factor 7-like 2 genetic polymorphisms and development of type 2 diabetes in a Chinese population
}

\author{
H.Y. Jia, Q.Z. Li and L.F. Lv \\ Department of Endocrinology, Henan Provincial People's Hospital, \\ Zhengzhou, China \\ Corresponding author: H.Y. Jia \\ E-mail: jiahaiyya@163.com
}

Genet. Mol. Res. 15 (2): gmr.15028223

Received December 7, 2015

Accepted April 4, 2016

Published June 10, 2016

DOI http://dx.doi.org/10.4238/gmr.15028223

\begin{abstract}
We conducted a hospital-based case-control study to evaluate the relationship between the transcription factor 7-like 2 (TCF7L2) rs7903146 polymorphism and type 2 diabetes mellitus risk in a Chinese population. Genotyping of TCF7L2 rs7903146 was carried out using the polymerase chain reaction-restriction fragment length polymorphism method. A chi-square test revealed a statistically significant difference between the distributions of rs7903146 genotypes in type 2 diabetes mellitus patient and control groups (chi-square $=10.49, \mathrm{P}=0.005)$. Using unconditional logistic regression analysis, we observed that the TT genotype of this polymorphism was significantly correlated with increased risk of developing type 2 diabetes mellitus compared to the CC genotype [odds ratio $(\mathrm{OR})=2.31,95 \%$ confidence interval $(\mathrm{CI})=1.33-4.04$ ] Furthermore, we found that the rs 7903146 sequence variation was also significantly associated with susceptibility to this disease under dominant $(\mathrm{OR}=1.58,95 \% \mathrm{CI}=1.09-2.28)$ and recessive models
\end{abstract}


$(\mathrm{OR}=2.11,95 \% \mathrm{CI}=1.25-3.62)$. We conclude that the $T C F 7 L 2$ rs7903146 genetic polymorphism is independently associated with the risk of developing type 2 diabetes mellitus under co-dominant, dominant, and recessive models.

Key words: TCF7L2; rs7903146; Type 2 diabetes mellitus

\section{INTRODUCTION}

Type 2 diabetes mellitus is a chronic and complex disease characterized by insulin resistance and impaired insulin secretion, and represents a serious global health problem associated with high morbidity. It is estimated that there are approximately 92.4 million adults with type 2 diabetes mellitus and 148.2 million with prediabetes in China (Yang et al., 2010; Cai et al., 2013; Fu et al., 2013; Jiang et al., 2013). The etiology of this disease is not well understood. Environmental and genetic factors both contribute to the development of type 2 diabetes mellitus (Mrozikiewicz-Rakowska et al., 2015; Pearson, 2015). Previous genome-wide association studies have implicated many loci in the onset, prognosis, and severity of type 2 diabetes mellitus (Adeyemo et al., 2015; Wei et al., 2015).

Transcription factor 7-like 2 (TCF7L2) is located on chromosome 10q25.3 and is $216.86 \mathrm{~kb}$ in length. TCF7L2 expression is related to its proposed function in insulin secretion. Several previous studies have examined the role of the TCF7L2 rs7903146 polymorphism in the development of type 2 diabetes mellitus, but their results have been inconclusive (Assmann et al., 2014; Barros et al., 2014; Allahdini et al., 2015; GuewoFokeng et al., 2015; Liu et al., 2015; Nanfa et al., 2015; Yao et al., 2015; Yang et al., 2015). In this study, we conducted a hospital-based case-control investigation to evaluate the relationship between $T C F 7 L 2$ rs 7903146 and risk of developing type 2 diabetes mellitus in a Chinese population.

\section{MATERIAL AND METHODS}

\section{Subjects}

Between January 2013 and December 2014, 248 patients with type 2 diabetes mellitus and 267 control subjects without the disease were consecutively recruited from the Department of Endocrinology of Henan Provincial People's Hospital. Type 2 diabetes mellitus was diagnosed based on the World Health Organization-International Diabetes Federation criteria (WHO-IDF, 2006). Control subjects consisted of individuals who attended our hospital for a regular health examination, and all were confirmed as not having type 2 diabetes mellitus. Individuals with a history of diabetes, metabolic diseases or cancers were excluded.

Lifestyle and dietary data were collected using a self-designed questionnaire, and included sex, age, body mass index (BMI), and tobacco and alcohol consumption. Clinical data were gathered from medical record including hypertension, blood glucose, insulin and etc. The study was performed with the permission of the Institutional Review Board of Henan Provincial People's Hospital. Written informed consent was given by all subjects before participation. This study conformed to the Declaration of Helsinki. 


\section{Genotyping methods}

A peripheral blood sample $(5 \mathrm{~mL})$ was obtained from each participan. DNA was extracted from these samples using a QIAGEN Blood Mini Kit (QIAGEN, Hilden, Germany). Genotyping of TCF7L2 rs7903146 was carried out using the polymerase chain reaction (PCR)-restriction fragment length polymorphism method with the following primers: 5'CTG AAC AAT TAG AGA GCT AAG CAC TTT TTA GGT A-3' (forward) and 5'-TTT CAC TAT GTA TTG TTG CCA GTC AGC AAA CAC-3' (reverse). The length of the amplified fragment was $266 \mathrm{bp}$. The cycling conditions were as follows: $94^{\circ} \mathrm{C}$ for $5 \mathrm{~min} ; 35$ cycles of $94^{\circ} \mathrm{C}$ for $5 \mathrm{~s}, 63^{\circ} \mathrm{C}$ for $30 \mathrm{~s}$, and $72^{\circ} \mathrm{C}$ for $30 \mathrm{~s}$; and a final extension step at $72^{\circ} \mathrm{C}$ for $10 \mathrm{~min}$. The amplified products were digested with RsaI restriction enzyme. To determine purity and integrity, PCR products were separated using 3\% agarose gel electrophoresis and visualized by ultraviolet light.

\section{Statistical analysis}

Demographic, lifestyle, and clinical characteristics of type 2 diabetes mellitus patients and control subjects were compared by independent samples $t$-tests or chisquare tests. The distribution of TCF7L2 rs7903146 genotypes in the two groups was analyzed using chi-square tests. Deviation of genotype distributions from Hardy-Weinberg equilibrium (HWE) was assessed in the patient and control groups using the goodnessof-fit chi-square test. The association between TCF7L2 rs7903146 and type 2 diabetes mellitus was examined using logistic regression analyses, and odds ratios (OR) and 95\% confidence intervals $(95 \% \mathrm{CI})$ were calculated. Statistical analysis was conducted using SPSS 16.0 (SPSS Inc., Chicago, IL, USA). P values less than 0.05 were considered statistically significant.

\section{RESULTS}

The demographic and lifestyle characteristics of type 2 diabetes mellitus patients and control subjects are shown in Table 1. Chi-square tests showed that patients and controls were comparable in terms of age (chi-square $=0.15, \mathrm{P}=0.70)$, sex (chi-square $=1.51, \mathrm{P}=$ 0.22 ), BMI (chi-square $=3.33, \mathrm{P}=0.07$ ), tobacco smoking (chi-square $=0.45, \mathrm{P}=0.50$ ), and alcohol consumption (chi-square $=0.28, \mathrm{P}=0.60$ ). However, individuals with type 2 diabetes mellitus were more likely to develop hypertension (chi-square $=4.39, \mathrm{P}=0.04$ ) and have higher levels of fasting glucose $(t=5.73, \mathrm{P}<0.05)$, fasting insulin $(t=38.39, \mathrm{P}<$ $0.05)$, TC $(t=23.46, \mathrm{P}<0.05), \mathrm{TG}(t=31.43, \mathrm{P}<0.05)$, HDL-C $(t=2.34, \mathrm{P}<0.05)$, and LDL-C $(t=17.30, \mathrm{P}<0.05)$.

The distribution of TCF7L2 rs7903146 genotypes in the two groups is presented in Table 2. In the type 2 diabetes mellitus patient group, $125(50.40 \%), 73(29.44 \%)$, and $50(20.16 \%)$ individuals carried the CC, CT, and TT genotypes, respectively. In the control group, these genotypes were found in $165(61.80 \%), 74(27.72 \%)$, and $28(10.49 \%)$ subjects, respectively. A chi-square test revealed a statistically significant difference between type 2 diabetes mellitus patients and control subjects (chi-square $=10.49, \mathrm{P}=0.005$ ) regarding these distributions. TCF7L2 rs7903146 genotype frequencies deviated from HWE in both study groups, with $\mathrm{P}$ values less than 0.001 . 
Table 1. Demographic and lifestyle characteristics of type 2 diabetes mellitus patients and control subjects.

\begin{tabular}{|c|c|c|c|c|c|c|}
\hline Characteristic & Patients $(\mathrm{N}=248)$ & $\%$ & Controls $(\mathrm{N}=267)$ & $\%$ & Chi-square & $\mathrm{P}$ \\
\hline \multicolumn{7}{|l|}{ Age, years } \\
\hline$<50$ & 137 & 55.24 & 143 & 53.56 & & \\
\hline$\geq 50$ & 111 & 44.76 & 124 & 46.44 & 0.15 & 0.70 \\
\hline \multicolumn{7}{|l|}{ Gender } \\
\hline Female & 90 & 36.29 & 111 & 41.57 & & \\
\hline Male & 158 & 63.71 & 156 & 58.43 & 1.51 & 0.22 \\
\hline \multicolumn{7}{|l|}{ BMI } \\
\hline$<24$ & 148 & 59.68 & 180 & 67.42 & & \\
\hline$\geq 24$ & 100 & 40.32 & 87 & 32.58 & 3.33 & 0.07 \\
\hline \multicolumn{7}{|l|}{ Tobacco smoking } \\
\hline No & 165 & 66.53 & 185 & 69.29 & & \\
\hline Yes & 83 & 33.47 & 82 & 30.71 & 0.45 & 0.50 \\
\hline \multicolumn{7}{|l|}{ Alcohol consumption } \\
\hline No & 157 & 63.31 & 175 & 65.54 & & \\
\hline Yes & 91 & 36.69 & 92 & 34.46 & 0.28 & 0.60 \\
\hline \multicolumn{7}{|l|}{ Hypertension } \\
\hline No & 192 & 77.42 & 226 & 84.64 & & \\
\hline Yes & 56 & 22.58 & 41 & 15.36 & 4.39 & 0.04 \\
\hline Fasting glucose $(\mathrm{mM})$ & & $8.43 \pm 2.47$ & & $4.82 \pm 1.35$ & 5.73 & $<0.05$ \\
\hline Fasting insulin $(\mathrm{mM})$ & & $59.12 \pm 14.65$ & & $51.6 \pm 15.11$ & 38.39 & $<0.05$ \\
\hline $\mathrm{TC}(\mathrm{mg} / \mathrm{dL})$ & & $184.55 \pm 17.35$ & & $154.53 \pm 11.25$ & 23.46 & $<0.05$ \\
\hline $\mathrm{TG}(\mathrm{mg} / \mathrm{dL})$ & & $174.26 \pm 14.12$ & & $131.50 \pm 16.55$ & 31.43 & $<0.05$ \\
\hline HDL-C (mg/dL) & & $47.82 \pm 1.81$ & & $46.10 \pm 11.42$ & 2.34 & $<0.05$ \\
\hline LDL-C $(\mathrm{mg} / \mathrm{dL})$ & & $134.26 \pm 11.64$ & & $118.71 \pm 8.63$ & 17.30 & $<0.05$ \\
\hline
\end{tabular}

$\mathrm{BMI}=$ body mass index, $\mathrm{TC}=$ total cholesterol, $\mathrm{TG}=$ triglycerides, $\mathrm{HDL}-\mathrm{C}=$ high-density lipoprotein cholesterol, LDL-C $=$ low-density lipoprotein cholesterol.

Table 2. Distribution of TCF7L2 rs7903146 polymorphism genotypes in type 2 diabetes mellitus patient and control groups.

\begin{tabular}{l|c|c|c|c|c|c|c|c}
\hline Genotype & Patients & $\%$ & Controls & $\%$ & Chi-square & P value & \multicolumn{2}{|c}{ P value for HWE } \\
\cline { 3 - 8 } & & & & & & & \\
\hline CC & 125 & 50.40 & 165 & 61.80 & & & & \\
\hline CT & 73 & 29.44 & 74 & 27.72 & & & $<0.001$ \\
\hline TT & 50 & 20.16 & 28 & 10.49 & 10.49 & 0.005 & $<0.001$ & $<0.001$ \\
\hline
\end{tabular}

HWE $=$ Hardy-Weinberg equilibrium.

Using unconditional logistic regression analysis, we established that the TT genotype of TCF7L2 rs7903146 was significantly correlated with increased risk of developing type 2 diabetes mellitus compared to the CC genotype, with an adjusted OR (and 95\% CI) of 2.31 (1.33-4.04; Table 3). Furthermore, we observed that the TCF7L2 rs7903146 genetic polymorphism was significantly associated with susceptibility to this disease under dominant $(\mathrm{OR}=1.58,95 \% \mathrm{CI}=1.09-2.28)$ and recessive models $(\mathrm{OR}=2.11,95 \% \mathrm{CI}=1.25-3.62)$.

Table 3. Association between the TCF7L2 rs7903146 polymorphism and risk of type 2 diabetes mellitus.

\begin{tabular}{|c|c|c|c|c|c|c|}
\hline Model & Patients & $\%$ & Controls & $\%$ & OR $(95 \% \mathrm{CI})^{1}$ & $\mathrm{P}$ value \\
\hline \multicolumn{7}{|c|}{ Co-dominant } \\
\hline $\mathrm{CC}$ & 125 & 50.4 & 165 & 61.8 & 1.0 (Ref.) & - \\
\hline $\mathrm{CT}$ & 73 & 29.44 & 74 & 27.72 & $1.30(0.86-1.98)$ & 0.19 \\
\hline TT & 50 & 20.16 & 28 & 10.49 & $2.31(1.33-4.04)$ & 0.001 \\
\hline \multicolumn{7}{|c|}{ Dominant } \\
\hline $\mathrm{CC}$ & 125 & 50.4 & 165 & 61.8 & 1.0 (Ref.) & - \\
\hline $\mathrm{CT}+\mathrm{TT}$ & 123 & 49.6 & 102 & 38.2 & $1.58(1.09-2.28)$ & 0.01 \\
\hline \multicolumn{7}{|c|}{ Recessive } \\
\hline $\mathrm{CC}+\mathrm{CT}$ & 198 & 79.84 & 239 & 89.51 & 1.0 (Ref.) & - \\
\hline TT & 50 & 20.16 & 28 & 10.49 & $2.11(1.25-3.62)$ & 0.003 \\
\hline
\end{tabular}

${ }^{1}$ Adjusted for age, sex, hypertension, fasting glucose, fasting insulin, total cholesterol $(t=23.46, \mathrm{P}<0.05)$, triglycerides, and high- and low-density lipoprotein cholesterol. $\mathrm{OR}=$ odds ratio; $\mathrm{CI}=$ confidence interval, Ref. $=$ reference. 


\section{DISCUSSION}

In the present study, we investigated the role of the TCF7L2 rs7903146 polymorphism in the pathogenesis of type 2 diabetes mellitus. Our findings indicated that the TT genotype of this variant significantly influences the development of this disease compared to the CC genotype, and that the TCF7L2 rs7903146 polymorphism is associated with increased risk of type 2 diabetes mellitus under the dominant and recessive models in the Chinese population examined.

TCF7L2 is a member of Wnt signaling pathway, and plays an important role in the development of embryonic cellular (Cauchi et al., 2006). A previous experimental study has indicated that this pathway is closely associated with insulin secretion (Papadopoulou et al., 2011). Moreover, the TCF7L2 gene is involved in modifying the expression of insulin and glucagon protein through Wnt signaling. A previous study has demonstrated a significant association between high expression of TCF7L2 in pancreatic beta cells and glucose metabolism (Takamoto et al., 2014). Zhou et al. (2014) reported that the T allele of rs7903146, associated with diabetes risk, correlates with increased TCF $2 L 2$ expression and reduced insulin levels and secretion, thus the affected protein may regulate insulin production and the pathogenesis of type 2 diabetes mellitus. In a study of a healthy Chinese population, Wang et al. (2015) found that TCF7L2 genetic variation is significantly associated with fasting plasma glucose and triglyceride indexes.

To date, several studies have tested the association between TCF7L2 genetic variations and risk of developing type 2 diabetes mellitus (Assmann et al., 2014; Barros et al., 2014; OuhaibiDjellouli et al., 2014; Guewo-Fokeng et al., 2015; Nanfa et al., 2015; Yang et al., 2015; Yao et al., 2015). Assmann et al. (2014), Guewo-Fokeng et al. (2015), and Ouhaibi-Djellouli et al. (2014) conducted investigations to assess the role of the TCF7L2 rs7903146 polymorphism in the pathogenesis of this disease, reporting that this sequence variant is associated with susceptibility to type 2 diabetes mellitus in Caucasians. In studies of Chinese populations, Yao et al. (2015) and Yang et al. (2015) determined that the TCF7L2 rs12255372 polymorphism may also contribute to the risk of developing this condition. However, some investigations have reached inconsistent conclusions (Barros et al., 2014; Pourahmadi et al., 2015). For instance, Barros et al. (2014) failed to establish a significant correlation between the TCF7L2 rs7903146 variant and development of type 2 diabetes mellitus in Brazilian individuals. In addition, Pourahmadi et al. (2015) conducted a study of 200 patients and 200 control subjects from an Iranian population, in which they found no influence of the TCF7L2 rs7903146 and rs12255372 polymorphisms on the incidence of this disease. The current work suggests that the TCF7L2 rs7903146 variation may affect susceptibility to type 2 diabetes mellitus in a Chinese population.

In conclusion, we observed that the TCF7L2 rs7903146 genetic polymorphism is independently associated with risk of developing type 2 diabetes mellitus under co-dominant, dominant, and recessive models. Further studies involving a greater number of ethnicities and larger sample sizes are greatly required to verify our findings.

\section{Conflicts of interest}

The authors declare no conflict of interest.

\section{ACKNOWLEDGMENTS}

We thank for the help from staffs for helping us collecting the blood samples in Henan Provincial People's Hospital. 


\section{REFERENCES}

Adeyemo AA, Tekola-Ayele F, Doumatey AP, Bentley AR, et al. (2015). Evaluation of genome wide association study associated type 2 diabetes susceptibility loci in Sub Saharan Africans. Front. Genet. 6: 335. http://dx.doi.org/10.3389/ fgene.2015.00335

Allahdini M, Kamalidehghan B, Akbari L, Azadfar P, et al. (2015). Prevalence of the rs7903146C $>$ T polymorphism in TCF7L2 gene for prediction of type 2 diabetes risk among Iranians of different ethnicities. Drug Des. Devel. Ther. 9: $5835-5841$.

Assmann TS, Duarte GC, Rheinheimer J, Cruz LA, et al. (2014). The TCF7L2 rs7903146 (C/T) polymorphism is associated with risk to type 2 diabetes mellitus in Southern-Brazil. Arq. Bras. Endocrinol. Metabol. 58: 918-925.

Barros CM, Araujo-Neto AP, Lopes TR, Barros MA, et al. (2014). Association of the rs7903146 and rs12255372 polymorphisms in the TCF $7 L 2$ gene with type 2 diabetes in a population from northeastern Brazil. Genet. Mol. Res. 13: 7889-7898. http://dx.doi.org/10.4238/2014.September.29.1

Cai H, Cai J and Tao G (2013). Association of toll-like receptor 4 polymorphisms with type 2 diabetes mellitus. APMIS 121: 605-611. http://dx.doi.org/10.1111/apm.12027

Cauchi S, Meyre D, Dina C, Choquet H, et al. (2006). Transcription factor TCF7L2 genetic study in the French population: expression in human beta-cells and adipose tissue and strong association with type 2 diabetes. Diabetes 55: 29032908. http://dx.doi.org/10.2337/db06-0474

Fu XD, Sun XQ, Wang HY, Guo JF, et al. (2013). Genetic polymorphisms of the TLR4 gene and their association with susceptibility to type 2 diabetes mellitus in the Chinese population. Genet. Mol. Res. 12: 3813-3820. http://dx.doi. org/10.4238/2013.September.19.13

Guewo-Fokeng M, Sobngwi E, Atogho-Tiedeu B, Donfack OS, et al. (2015). Contribution of the TCF7L2 rs7903146 $(\mathrm{C} / \mathrm{T})$ gene polymorphism to the susceptibility to type 2 diabetes mellitus in Cameroon. J. Diabetes Metab. Disord. 14: 26. http://dx.doi.org/10.1186/s40200-015-0148-z

Jiang ZS, Wang SX, Jia HX, Wang J, et al. (2013). Association of toll-like receptor 4 polymorphisms with type 2 diabetes mellitus. Inflammation 36: 251-257. http://dx.doi.org/10.1007/s10753-012-9541-7

Liu XH, Xie CG, An Y, Zhang XX, et al. (2015). Meta-analysis of the association between the rs7903146 polymorphism at the TCF7L2 locus and type 2 diabetes mellitus susceptibility. Genet. Mol. Res. 14: 16856-16862. http://dx.doi. org/10.4238/2015.December.14.12

Mrozikiewicz-Rakowska B, Maroszek P, Nehring P, Sobczyk-Kopciol A, et al. (2015). Genetic and environmental predictors of chronic kidney disease in patients with type 2 diabetes and diabetic foot ulcer: a pilot study. J. Physiol. Pharmacol. 66: 751-761.

Nanfa D, Sobngwi E, Atogho-Tiedeu B, Noubiap JJ, et al. (2015). Association between the TCF7L2 rs12255372 (G/T) gene polymorphism and type 2 diabetes mellitus in a Cameroonian population: a pilot study. Clin. Transl. Med. 4: 17. http://dx.doi.org/10.1186/s40169-015-0058-1

Ouhaibi-Djellouli H, Mediene-Benchekor S, Lardjam-Hetraf SA, Hamani-Medjaoui I, et al. (2014). The TCF7L2 rs7903146 polymorphism, dietary intakes and type 2 diabetes risk in an Algerian population. BMC Genet. 15: 134. http://dx.doi.org/10.1186/s12863-014-0134-3

Papadopoulou A, Lynch KF, Shaat N, Håkansson R, et al.; DiPiS Study Group (2011). Gestational diabetes mellitus is associated with TCF7L2 gene polymorphisms independent of HLA-DQB1*0602 genotypes and islet cell autoantibodies. Diabet. Med. 28: 1018-1027. http://dx.doi.org/10.1111/j.1464-5491.2011.03359.x

Pearson ER (2015). Dissecting the etiology of type 2 diabetes in the Pima Indian population. Diabetes 64: 3993-3995. http://dx.doi.org/10.2337/dbi15-0016

Pourahmadi M, Erfanian S, Moradzadeh M and Jahromi AS (2015). Non-association between rs7903146 and rs12255372 polymorphisms in transcription factor 7-like 2 gene and type 2 diabetes mellitus in Jahrom City, Iran. Diabetes Metab. J. 39: 512-517. http://dx.doi.org/10.4093/dmj.2015.39.6.512

Takamoto I, Kubota N, Nakaya K, Kumagai K, et al. (2014). TCF7L2 in mouse pancreatic beta cells plays a crucial role in glucose homeostasis by regulating beta cell mass. Diabetologia 57: 542-553. http://dx.doi.org/10.1007/s00125$\underline{013-3131-6}$

Wang J, Yan G, Zhang J, Gao K, et al. (2015). Association of LRP5, TCF7L2, and GCG variants and type 2 diabetes mellitus as well as fasting plasma glucose and lipid metabolism indexes. Hum. Immunol. 76: 339-343. http://dx.doi. org/10.1016/j.humimm.2015.03.005

Wei FJ, Cai CY, Yu P, Lv J, et al. (2015). Quantitative candidate gene association studies of metabolic traits in Han Chinese type 2 diabetes patients. Genet. Mol. Res. 14: 15471-15481. http://dx.doi.org/10.4238/2015.November.30.25

WHO-IDF (2006). Definition and diagnosis of diabetes mellitus and intermediate hyperglycemia: report of a WHO/IDF

Genetics and Molecular Research 15 (2): gmr.15028223

CFUNPEC-RP www.funpecrp.com.br 
consultation. Available at [http://www.idf.org/webdata/docs/WHO_IDF_definition_diagnosis_of_diabetes.pdf]. Accessed October 1, 2014.

Yang SH, Dou KF and Song WJ (2010). Prevalence of diabetes among men and women in China. N. Engl. J. Med. 362: 1090-1101. http://dx.doi.org/10.1056/NEJMoa0908292

Yang Y, Xu JR, Wang YJ and Liu XM (2015). Association of TCF7L2 gene polymorphisms with susceptibility to type 2 diabetes mellitus in a Chinese Hui population. Genet. Mol. Res. 14: 10064-10071. http://dx.doi.org/10.4238/2015. August. 21.13

Yao H, Wang Z, Wang T, Ma Y, et al. (2015). Association of TCF7L2 genetic polymorphisms with type 2 diabetes mellitus in the Uygur population of China. Int. J. Environ. Res. Public Health 12: 11797-11814. http://dx.doi.org/10.3390/ ijerph120911797

Zhou Y, Park SY, Su J, Bailey K, et al. (2014). TCF7L2 is a master regulator of insulin production and processing. Hum. Mol. Genet. 23: 6419-6431. http://dx.doi.org/10.1093/hmg/ddu359 